\title{
Research of College Students' Career Planning and Employment
}

\author{
Yuan Song \\ Xi'an International University, Xi'an, 710077, China
}

\author{
Keywords: College students, Career planning, Effective employment
}

\begin{abstract}
With the improvement of people's living standards and development of social, higher education gradually become popular, prompting a rapid increase in the number of students, also appear obvious employment problems, college students career planning is an effective way to solve the employment of college students, thus, need to Students early career planning, based on planning targeted training, How to make college students' career planning, to improve the efficiency of employment, is the main focus of future research. This paper analyzes the connotation of college students 'career planning and employment relations, and the impact of college students' career planning for effective employment.
\end{abstract}

\section{Introduction}

At present, the college students' employment and college students' career planning is very hot, but it's also a difficult problem. The former is whole communities and countries are concerned about and can't attack the problem in a short time, is also the university need to solve the problem. The latter is a college student life struggle, whether can realize its own value, is not individual can assert. Until the 1960s, when Western countries first began to focus on employment issues and related theories, career guidance beginning seekers more in line with social needs and demands. With the continuous development of the market economy system, our country began focus on employment issues In the nineties, the rapid development of higher education, the basic system becomes autonomous university career, two-way choice, clearly highlights the difficult employment phenomenon, the job market has become more and more chaos and disorder, society began extensive attention College' Career Planning.

\section{The connotation and meaning of college students' career planning}

Career planning (career planning) is career planning. Career planning is the impact of its employment environment, employability, university students and other relevant conditions for entrepreneurship, careers, employment offers action program to determine, operational goals and direction of the process. From the dynamic analyzes, career preparation and career planning is the planning of their own career development direction, reflecting the potential to predict the future, real-world conditions, the ability to influence factors, the development of college students' career planning and planning related activities to achieve practical goals. Static analyzes, the main contents include career planning is the occupational environment analysis, career goals, career orientation, professional practice strategy, professional competence analysis programs. The main purpose of career planning is actually able to provide the ability to understand their own and conditions for students, a comprehensive analysis of factors under the premise, to make a reasonable career orientation and career choices.

\section{For the determination of college students' development goals and direction}

Under the influence of the traditional theory based, whether it is the students themselves or family, or school, community with relatively clear objectives, the ultimate goal is to college students themselves always in tremendous pressure, so, after the completion of the University of goals to achieve, most students will be some relaxation of thought, forming a development goal and the development direction of the more obscure. For these problems, we need to have a goal, a step, a planned career plan, prompting students in the learning stage all know how their own learning and 
hard work, clear objectives and direction of their own development, to ensure the healthy growth of college students, with colorful life ${ }^{[1]}$.

\section{For college students' self-awareness and self-image}

Domestic most of the education system is in the traditional model, many students and parents are still in college as the most important goal in life, few people go to college as a future career preparation and accumulation。After entering the university, so, when students take reasonable planning their own career, I want to do, who I am, who I want to be, what can I do, issues related to ensure students can fully understand and grasp their own needs and life, prompting students development potential aptitude, personality traits, provide value for future employment.

\section{For college students realize their potential and help improve the competitiveness}

With increasingly fierce competition, the reform era, society in the process of college students' study, can't fully understand and analyze the importance and significance of career planning, many college students are graduated with a resume delivery around, waste a lot of time, money and experience, finally can't get a satisfactory job, want to reflect its own advantages in the fierce competition in society, needs to do a good job in college students' career planning, clear their own goals, and then carries on the practice, be able to get a certain effect, and is more scientific and economic way.

\section{The relationship between college students' career planning and employment}

From basic definitions can be found that college students' career planning the implementation of college students' career planning basic purpose is based on the choice of career and career planning to reflect their own value. Employment is just vocational college students' career planning starting point, but it's not the end. College students' career planning is not the guidance of university students' employment, career counseling and career guidance are prompting measures of college students' personal career development, but there is a certain difference, based on the theory of Donald E.Super career planning can be found, mainly including five stages, namely growth, exploration, establish, maintain and recession, employment is career exploration period, is an important period of development itself. College students' self development needs certain base, employment is the key to the development of college students, is also a turning point. Career is the longest time in his life, the most important experience. As a result, the employment to a part of the career counseling. Compared with career guidance, career guidance is more comprehensive, the whole and the whole counseling process, plays a more important role and significance.

Employment is the new starting point in the process of career planning, but it's not the end of the career. Also can be said to be the career planning is the process of dynamic, constantly adjust according to oneself circumstance, career planning is the engineering insist for a long time, the university career planning should not only from the knowledge of important effective way to improve college students' employment ability is actually a good college students' career planning. At present, with more and more diversified forms of college students' career planning counseling, many colleges and universities have established the related career planning course. Is becoming more and more attention and emphasis on career planning, and appropriate to carry out the corresponding activities. Tsinghua university, for example, establish the school pre-service education network, and using the Internet teaching in the form of a career planning guidance to students, at the start of trial stage, has gained the attention of students and welcome, has 1142 hits. Many experts pointed out that this way doesn't guarantee that can improve the employment rate, but can increase employment opportunities. Currently, the main hope awareness by cultivating college students career planning, to ensure effective planning students, and constantly improve their own quality in order to improve the overall training, employment face [2]. 


\section{The influence of the career planning of university students for the job}

\section{Shorten the period of employment}

Employment time that is in college students began to prepare to find a job, until the time the process of successful employment, early on college students' career planning can shorten employment exert maximum. As much as possible so that students can understand and master the employment-related policies and information, analyzing their abilities, interests, strengths, personality, weaknesses, and capacity needs to learn a lot of information professionals and help, and to calm rational analysis of their strengths, suitable job, they want to engage in the occupation, with the relevant capacity in the profession. For it is no social experience and work experience of the students, we need to continue to improve college students' career planning and education efforts.

\section{Effectively control the disorder in the talent market and high flow problem}

In the process of career planning, you can make college students more rational evaluation of their own, to the community in their own right, rational, accurate and professional orientation, to ensure effective control of college graduates in the job market at this stage appears blind choice of occupation and breach of contract rate, thereby reducing the student and the employer in respect of unemployed phenomenon no one is available, prompting students can complete employment and promote social harmony and stability and healthy development [3].

\section{Clear job target and employment direction}

Due to the continuous development of society, the emergence of more and more pressure on employment careers, only with good results, and in formal employment ago everything ready to do good, to be able to find more jobs, better face social choice, further great success on the premise of employment. American psychologist John Holland and reasonable personal career aptitude is divided into six areas: pioneering, research, conventional type, art type, the actual type of social model, and also from the professional type reasonably be divided into six, Vocational Aptitude theory is mainly adapted to the type of career and vocational aptitude. All occupations in society are able to get the corresponding type of occupation in the above-mentioned aptitudes, so, at the time of employment, college students need to fully analyze the relationship between occupational and vocational aptitude. At this stage, the number of domestic students themselves able to clearly recognize career planning is still relatively small, so in the course of employment, the college students will be a corresponding blindness, it can be said that most of them are in reasonable career choice college students, not college students according to their actual situation to a reasonable choice of occupation. Based on actual surveys indicate that only $51.4 \%$ college students career planning, with vague ideas and thoughts. $17.6 \%$ of the students for their future career planning is still very confused, I do not know what to do next. With only 27.6 percent of the students will be planning its own next three to five years.

\section{Increase the employment ability and competitiveness}

Reasonable and effective career planning Students need Students can first full recognition of their own situation, and the combination of the relevant planning theory, determine their values, personal ability, personality, interests, temperament, personality, defects to the development of vocational and choice of occupation related factors have a great impact. So, first of all college students analyze their own strengths and weaknesses, correct understanding of their actual characteristics, and reasonable choice of employment goals and direction. At this stage, there is a relatively common problem students, is the lack of clear objectives learning. Therefore, the need to constantly improve the career planning concept and awareness, promote earlier Students can establish and clear direction and goals of the struggle, understand and grasp the current situation of social employment, social need career, career development, and between reality and personal development goals gap, prompting Students can continue to enrich student life, lay the foundation for future employment. For the future to quickly integrate into the society, students need for timely planning future goals and direction, no plan to change the past or planned late phenomenon, from the beginning, when college students entering college students, we need to make the appropriate combination of future planning, in an effort to learn specialized courses Students Meanwhile, the need to improve their knowledge of a planned structure [4]. 


\section{Early career planning can achieve tripartite win-win situation}

From the employment and the relationship between college students' career planning, college students belong to the exploration stage of life, if you can earlier enlightenment, is more advantageous for future employment. With the social development and progress, national vocational education plan gradually progress towards the earlier direction. Western countries, from kindergarten education career planning, and people throughout the stage, the formation of life at all stages of the implementation of the concept of career education. To ensure that students in the professional skills and knowledge have the time, we can more fully understand ourselves, and proactive choose their own path in life. Given the country affected by the traditional education, at present, many domestic students are in high school to the university entrance exam as the basic goal, after entering college students, will suddenly can not find the goal in life, the future is very confused. After continuous research can be found, the university began increasing emphasis on career planning problem, a university student in the neighboring graduation before considering their own employment problems, just need to start school on a clear career plan itself, and innovative ways. At this stage, for example, many colleges and universities have established career planning Students Association, under the supervision and guidance of personnel by college students build self-development, self-management is not profitable, but with guidance, professionalism, service and academic organizations. Society is established on the basis of school, we need to play the role of students as much as possible, using a variety of modalities to continue to penetrate the concept of career planning. Expanding students' career development and planning their own vision, but also can be a reasonable and effective employment guidance for schools to provide protection and infrastructure. Students themselves professional orientation for the development of enterprises have a certain sense, however, in carrying out our college students' career planning is still relatively late, there is a certain gap with advanced countries in the West, can not directly copy the Western theory and practice, to consider their own problems and insufficient to establish reasonable localization advanced theory, to ensure compliance with national development needs [5].

\section{Conclusion}

Overall, college students employment is not just looking for a job, need to be scientific, the right career choice, and the planning of the implementation is responsible for college students' career planning has very big effect, promote the fashion of the career planning analysis, for after the development of vocational college students to provide a certain basis and guarantee.

\section{References}

[1] Zhu Xiaofei, Liu Zhiguo. Reasonable positioning yourself achieving successful employment oral department. Seeing light professional obtain employment work special research. Journal of health vocational education, 2011, 29 (1) : 11-12

[2] Xia Yanfeng, Yan Xiafeng. College graduates career planning education front and way to undertake sexual explore. Journal of education and profession, 2014 (30) : 97-98.

[3] Li Shenliang, Dehua Yi, Sun zhenhui , etc. The financial crisis problem of college students' career planning and employment under the psychological pressure of study, college students as the object of investigation in jiangxi nanchang area. Science and technology information (academic), 2010 (36) : 37, 40.

[4] Jiang Rongtao. College students' career planning and the reform of higher education personnel training mode. Journal of xiangtan university (philosophy and social sciences edition), 2014, 28 (3) : 139-142. 
[5] Zhang Mingjie, Liu Mingyue. The teaching effectiveness of college students' career planning curriculum, based on the Inner Mongolia agricultural university career planning course teaching practice. Journal of front, 2012 (21) : 147-150. 